\title{
Bilateral Staged Primary Total Knee Arthroplasty: Are Patients Less Pleased with their Second Side?
}

\section{Mehdi Suzangar, MD, MRCS, MCh (T\&O), EBOT;; Colin Esler, BMesSci (Hons), BM, BS, FRCS (T\&O); James Kennedy, MBChB, BSC (Hons), MRCS; Urjit Chatterji, BSc (Hons), MBBS (Hons), FRCS (T\&O)}

Department of Trauma and Orthopaedics, University Hospitals of Leicester, Leicester, UK

\section{${ }^{*}$ Corresponding author}

Mehdi Suzangar, MD, MRCS, MCh (T\&O), EBOT

Senior Arthroplasty Fellow, Department of Trauma and Orthopaedics, University Hospitals of Leicester, Leicester, UK; Tel. 0044-7723368492;

E-mail:Suzangar_amir@yahoo.com

\section{Article information}

Received: January $3^{\text {rd }}, 2019$; Revised: February $~^{\text {st }}$, 2019; Accepted: February $3^{\text {rd }}$, 2019 Published: February $21^{\text {st }}, 2019$

\section{Cite this article}

Suzangar M, Esler C, Kennedy J, Chatterji U. Bilateral staged primary total knee arthroplasty:Are patients less pleased with their second side? Orthop Res Traumatol Open J. 2019; 4(I): I-5. doi: I0.17I40/ORTOJ-4-II4

\section{ABSTRACT}

\section{Background}

The available literature on the reported patient satisfaction following bilateral staged primary total knee arthroplasty (TKA) is limited. The purpose of our study is to compare patient-reported satisfaction following bilateral non-simultaneous TKA performed in a single unit.

\section{Methods}

We retrospectively analyzed our regional database, the Trent and Wales Arthroplasty Audit Group (TWAAG). Patients who had bilateral staged TKA in the University Hospitals of Leicester, UK, between 1990 and 2007 and had completed a 12-month post-operative questionnaire were included in the study.

\section{Results}

One thousand one patients were included in the study. 824 patients $(82.3 \%)$ reported being satisfied with both of their primary TKAs. $91 \%$ and $88 \%$ reported being satisfied with their TKA respectively for the first and second sides. A chi-squared test revealed that the difference in satisfaction rates between the first and second side TKA was statistically significant. 86 patients were pleased with their first side but not pleased/unsure with the second side. On the other hand, 55 patients were pleased with their second side but not pleased/unsure with the first side. This difference was also statistically significant.

\section{Conclusion}

In our study, more patients were pleased following their first side compared to their second side TKA.

\section{Keywords}

Bilateral total knee replacement; Bilateral staged total knee arthroplasty (TKA); Patient satisfaction.

\section{INTRODUCTION}

$\mathrm{T}$ otal knee arthroplasty (TKA) is a widely accepted treatment for patients with end-stage degenerative and inflammatory arthritis. Patient-reported satisfaction following surgery is an important outcome measure following TKA. ${ }^{1-15}$ The reported patient-reported satisfaction following TKA in the literature varies, however current literature suggests that up to $20 \%$ of patients are not satisfied with their outcomes following this surgery. ${ }^{3,10,13-14}$ Failure to meet patient expectation is one of the most important factors in patient dissatisfaction following surgery. ${ }^{4,9,11,15-16}$ Hepinstall et $a l,{ }^{17}$ has demonstrated that amongst the different pre-operative contributors to TKA expectations, a history of a previous joint arthroplasty was associated with significantly lower expectations as compared to patients without a prior joint arthroplasty.

On the other hand, the currently available literature on the outcomes for bilateral staged TKA has little focus on patient reported satisfaction following surgery and the available limited literature on patient reported satisfaction is contradictory. In a retrospective study of 668 staged bilateral $\mathrm{TKA},{ }^{18}$ the authors defined a minimal clinically important improvement (MCII) as an improvement in the Oxford Knee Scores of more than five points if achieved one year after their TKA and found that the outcomes following the second side TKA were inferior to the first side. In their study, $87.6 \%$ of patients achieved MCII following 
their second TKA as compared to $92.7 \%$ following their first TKA, the difference of which was statistically significant $(p=0.002)$. The outcome of the second side TKA in their study was independent of the time interval between the staged bilateral TKA. In another study, ${ }^{19}$ the authors retrospectively compared 93 patients with bilateral staged TKA with different time intervals between the stages and found that patient satisfaction was significantly better for the second TKA compared to the first TKA if the interval between the two TKA was between 24-26-months.

The aim of this study was to compare patient-reported satisfaction between the two sides in patients who underwent bilateral staged TKA. Considering the theory that having had a previous TKA which is usually on the more painful or more arthritic knee can lead to potential higher expectations for their second primary TKA, we hypothesized that patients will report a lower satisfaction rate following their second side staged TKA.

\section{PATIENTS AND METHODS}

We performed a retrospective analysis of prospectively collected data from our regional joint register, the Trent and Wales arthroplasty audit group (TWAAG). The TWAAG database provided demographic and procedure related information on patients who had TKA in the Trent and Wales regions and included patients' BMI, the level of operating surgeons (Consultant, Registrar, Others including staff grade surgeons), type of implant used (PFC-CR; DePuy, PFCPS; Depuy, Nexgen-CR; Zimmer, Nexgen-PS; Zimmer and PCA Stryker), whether or not patella resurfacing was also performed, intra-operative complications.

A standardized validated ${ }^{20}$ questionnaire (Appendix 1) which included a question on their satisfaction (pleased, not pleased or unsure) was posted to all patients 12-months postoperatively. Patients who had undergone bilateral staged TKA between 1990 and 2007 in Leicester and responded to their post-operative questionnaire were included in the study and a retrospective analysis of the collected data was performed. We excluded patients in whom the satisfaction question was not completed for one or both sides.

Statistical analysis was performed using the two-tailed fisher exact test and chi-square tests for our analysis.

\section{RESULTS}

A total of 1001 patients (542 female, 459 male) were included in this study. The mean age patients at the time of the first side TKA was 68.7 years ( $\mathrm{SD}=8.3$ years) and the mean age for the second side TKA was 71.4 years ( $\mathrm{SD}=7.9$ years). The average time gap between the first and second TKA in the sample was 780-days, ranging from 2-days to 5317-days. From 1001 patients who underwent their first side TKA, 910 patients $(91 \%)$ reported to be pleased and 91 patients $(9.1 \%)$ were either not pleased or unsure about their satisfaction (37 patients were not pleased and 54 patients were unsure). For the second side TKA, 879 patients (88\%) reported to be pleased with their TKA, and 122 patients $(12 \%)$ were either not pleased or unsure about their satisfaction following their second side TKA (54 patients were not pleased and 68 patients were unsure). A chi-squared two-tailed test was performed which revealed a statistically significant difference in the patient-reported satisfaction between the two sides $(p=0.025)$.

From 1001 patients, 86 patients $(8.6 \%)$ were only satisfied with their first side TKA and 55 patients $(5.5 \%)$ were only satisfied with their second side TKA. Fisher exact test revealed that this difference was also statistically significant $(p=0.014)$.

From 1001 patients, 824 patients (82.3\%) reported being satisfied with both of their primary TKAs. Eleven patients $(1 \%)$ were not satisfied with both sides and 14 patients $(1.4 \%)$ were unsure about their satisfaction following both side TKAs. Therefore, 849 patients (85\%) reported similar satisfaction/ pleasure following their knee replacement for both sides. The remaining 152 patients $(15 \%)$ had different satisfaction/pleasure reports between the two sides.

Table 1 shows the breakdown of patient-reported satisfaction following their staged bilateral TKA.

\begin{tabular}{|c|c|c|}
\hline $\begin{array}{l}\text { Patient-reported satisfaction following bilat- } \\
\text { eral staged TKA }\end{array}$ & Number & Percentage \\
\hline Pleased with both side TKA & 824 & $82.3 \%$ \\
\hline Not pleased with both side TKA & 11 & $1 \%$ \\
\hline Unsure about both side TKA & 14 & $1.4 \%$ \\
\hline $\begin{array}{l}\text { Pleased with first side only (Not pleased/unsure } \\
\text { with second side) }\end{array}$ & 86 & $0.86 \%$ \\
\hline $\begin{array}{l}\text { Pleased with second side only (Not pleased/unsure } \\
\text { with second side) }\end{array}$ & 55 & $0.55 \%$ \\
\hline $\begin{array}{l}\text { Unsure about their first side and not pleased with } \\
\text { the contralateral side }\end{array}$ & 5 & $0.5 \%$ \\
\hline $\begin{array}{l}\text { Not pleased with their first side and unsure about } \\
\text { contralateral side }\end{array}$ & 6 & $0.6 \%$ \\
\hline Total & 1001 & $100 \%$ \\
\hline
\end{tabular}

\section{DISCUSSION}

Although there has been a lot of focus on patient-reported satisfaction as one of the important patient-reported outcome measures (PROMS) for unilateral TKA, ${ }^{1-15,21}$ there is a paucity of evidence on patient-reported satisfaction following bilateral staged TKA. Amongst various factors which can influence patient-reported satisfaction after TKA, patients' previous experience of a contralateral TKA can affect theirs after their next TKA, which could reflect on their reported satisfaction following their second TKA. Although one could expect that the previous experience of the whole process of pre-operative, operative and post-operative period, should provide the patients with better understanding and more realistic expectations, which could reflect as a higher satisfaction following their second side TKA, this is not always seen in practice.

We have retrospectively analyzed a prospectively col- 
lected regional arthroplasty database (TWAAG). We evaluated the patient-reported satisfaction in 1001 patients who had undergone bilateral staged TKA in Leicester. Our findings have shown that although patient-reported satisfaction one year after each TKA, was relatively high considering the current standards $(90.9 \%$ after the first side and $88 \%$ after the second TKA), a larger proportion of patients did not report to be pleased with their second side TKA the difference of which is statistically significant $(p=0.025)$. Also amongst the patients whom only reported to be pleased with one of the two sides TKA, a larger proportion was pleased with their first side TKA ( $86 \%$ vs. $55 \%)$ which was again statistically significant $(p=0.014)$.

We acknowledge that this study has several limitations. Firstly, although our study is relatively large numbered, considering the fact that patient-reported satisfaction is a multifactorial outcome, a higher number of patients would have added to the validity of this study. Secondly, we did not specifically look for post-operative complications after each TKA, which could affect patient-reported satisfaction. However, as part of the TWAAG form, intra-operative complications were recorded and there were no documented intra operative complications for any of these patients on the database. We found a total number of 19 patients who had revision surgery for different reasons from which there were 10 cases for the first side and 9 cases for the second side. These patients were not excluded from our study as they were almost equally distributed.

Finally, we did not specifically analyze the discrepancies in relation to the degree of surgeons and whether or not patella resurfacing was performed. Although the majority of cases were performed by consultants or associate specialists, as expected, in a University Teaching Hospital, Registrars and Fellows would perform supervised primary TKA. A study from 2018,22 has shown equivalent functional outcomes with no difference the post operative range of movement, operative time, length of stay or transfusion rates between primary TKA performed by supervised registrars and consultants. With regards to patella resurfacing, the vast majority of primary TKA performed in our unit were without patellar resurfacing. This is due to the fact that most level 1 randomized trial and subsequent meta-analyses have not shown a statistically significant difference in functional outcomes, knee scores, patient satisfaction, and anterior knee pain..$^{23-26}$

\section{CONCLUSION}

We have presented a relatively large numbered study specifically analyzing patient-reported satisfaction following bilateral staged TKA from our regional joint arthroplasty registry. We have shown that in our study, patients have reported a lower satisfaction rate following their second side primary TKA compared to the first side primary TKA. This information can improve patient counseling during the pre-operative period with a view to providing a more realistic expectation prior to surgery. We hope that this study would encourage larger numbered studies particularly from large databases such as national joint registries.

\section{ETHICS, REGISTRATION, FUNDING AND CONFLICTS OF INTEREST |}

All of the patients in the TWAAG dataset had given formal written consent for the use of their data for research purposes at the beginning of the data collection process. Although ethical approval had been granted for utilizing the dataset for research purposes by the Leicester University Ethics Committee, this project was separately enrolled as a service evaluation project to university hospitals of the Leicester Audit and Development Department. Our electronic database was password encrypted and anonymous to patients and operating surgeons.

There was no internal and external funding provided for this study and none of the authors had any personal or financial interest in the project.

\section{REFERENCES}

1. Anderson JG, Wixson RL, Tsai D, Stulberg SD, Chang RW. Functional outcome and patient satisfaction in total knee patients over the age of 75. J Arthroplasty. 1996; 11(7): 831-840. doi: 10.1016/ S0883-5403(96)80183-5

2. Baker PN, van der Meulen JH, Lewsey J, Gregg PJ, National Joint Registry for England and Wales. The role of pain and function in determining patient satisfaction after total knee replacement. J Bone Joint Surg Br. 2007; 89(7): 893-900. doi: 10.1302/0301-620X.89B7.19091

3. Baker PN, Rushton S, Jameson SS, Reed M, Gregg P, Deehan DJ. Patient satisfaction with total knee replacement cannot be predicted from pre-operative variables alone: A cohort study from the national joint registry for England and Wales. Bone Joint J. 2013; $95-$ B(10): 1359-1365. doi: 10.1302/0301-620X.95B10.32281

4. Bourne RB, Chesworth BM, Davis AM, Mahomed NN, Charron KD. Patient satisfaction after total knee arthroplasty: Who is satisfied and who is not? Clin Orthop Relat Res. 2010; 468(1): 57-63. doi: 10.1007/s11999-009-1119-9

5. Brokelman RB, van Loon CJ, Rijnberg WJ. Patient versus surgeon satisfaction after total hip arthroplasty. J Bone Joint Surg Br. 2003; 85(4): 495-498. doi: 10.1302/0301-620X.85B4.13411

6. Drexler M, Dwyer T, Chakravertty R, Farno A, Backstein D. Assuring the happy total knee replacement patient. Bone Joint J. 2013; 95-B (11 Suppl A): 120-123. doi: 10.1302/0301-620X.95B11.32949

7. Hamilton DF, Lane JV, Gaston P, et al. What determines patient satisfaction with surgery? A prospective cohort study of $4709 \mathrm{pa}-$ tients following total joint replacement. BMJ Open. 2013; 3(4). doi: 10.1136/bmjopen-2012-002525

8. Kim TK, Kwon SK, Kang YG, Chang CB, Seong SC. Functional disabilities and satisfaction after total knee arthroplasty in 
female Asian patients. J Arthroplasty. 2010; 25(3): 458-464.e1-2. doi: 10.1016/j.arth.2009.01.018

9. Lingard EA, Sledge CB, Learmonth ID, Kinemax Outcomes Group. Patient expectations regarding total knee arthroplasty: Differences among the United States, United Kingdom, and Australia. J Bone Joint Surg Am. 2006; 88(6): 1201-1207. doi: 10.2106/ JBJS.E.00147

10. Mancuso CA, Jout J, Salvati EA, Sculco TP. Fulfillment of patients' expectations for total hip arthroplasty. J Bone Joint Surg Am. 2009; 91(9): 2073-2078. doi: 10.2106/JBJS.H.01802

11. Nilsdotter AK, Toksvig-Larsen S, Roos EM. Knee arthroplasty: Are patients' expectations fulfilled? A prospective study of pain and function in 102 patients with 5-year follow-up. Acta Orthop. 2009; 80(1): 55-61. doi: 10.1080/17453670902805007

12. Noble PC, Conditt MA, Cook KF, Mathis KB. The John insall award: Patient expectations affect satisfaction with total knee arthroplasty. Clin Orthop Relat Res. 2006; 452: 35-43. doi: 10.1097/01. blo.0000238825.63648.1e

13. Robertsson O, Dunbar M, Pehrsson T, Knutson K, Lidgren L. Patient satisfaction after knee arthroplasty: A report on 27,372 knees operated on between 1981 and 1995 in Sweden. Acta Orthop Scand. 2000; 71(3): 262-267. doi: 10.1080/000164700317411852

14. Roberts VI, Esler CN, Harper WM. A 15-year follow-up study of 4606 primary total knee replacements. J Bone Joint Surg Br. 2007; 89(11): 1452-1456. doi: 10.1302/0301-620X.89B11.19783

15. Scott CE, Howie CR, MacDonald D, Biant LC. Predicting dissatisfaction following total knee replacement: A prospective study of 1217 patients. J Bone Joint Surg Br. 2010; 92(9): 1253-1258. doi: 10.1302/0301-620X.92B9.24394

16. Hepinstall MS, Rutledge JR, Bornstein LJ, Mazumdar M, Westrich GH. Factors that impact expectations before total knee arthroplasty. J Arthroplasty. 2011; 26(6): 870-876. doi: 10.1016/j. arth.2010.09.010

17. Leedham B, Meyerowitz BE, Muirhead J, Frist WH. Positive expectations predict health after heart transplantation. Health Psychol. 1995; 14(1): 74-79.
18. Lizaur-Utrilla A, Serna-Berna R, Vizcaya-Moreno MF, Martinez-Mendez D, Marco-Gomez L, Lopez-Prats FA. Comparison of functional outcomes between the first and second knee in staged bilateral total knee arthroplasty with diverse intervals between stages. J Arthroplasty. 2018; 33(9): 2863-2867. doi: 10.1016/j. arth.2018.04.033

19. Qutob M, Winemaker M, Petruccelli D, De Beer J. Staged bilateral total knee arthroplasty: Does history dictate the future? J Arthroplasty. 2013; 28(7): 1148-1151. doi: 10.1016/j.arth.2013.01.022

20. Scott CE, Bugler KE, Clement ND, Macdonald D, Howie CR, Biant LC. Patient expectations of arthroplasty of three hip and knee. J Bone Joint Surg Br. 2012; 94(7): 974-981. doi: 10.1302/0301-620X.94B7.28219

21. National Joint Registry. National Joint Registry for England and Wales. $10^{\text {th }}$ Annual Report. Website: http://www.njrcentre.org. uk/njrcentre/portals/0/documents/england/reports/10th_annual_report $/$ njr $\% 2010$ th $\% 20$ annual $\% 20$ report $\% 202013 \% 20$ b. pdf. 2013.

22. Beattie N, Maempel JF, Roberts S, et al. Surgery performed by supervised registrars does not adversely affect medium-term functional outcomes after total knee replacement. Ann R Coll Surg Engl. 2018; 100(1): 57-62. doi: 10.1308/rcsann.2017.0164

23. Burnett RS, Haydon CM, Rorabeck CH, Bourne RB. Patella resurfacing versus nonresurfacing in total knee arthroplasty: Results of a randomized controlled clinical trial at a minimum of 10 years' followup. Clin Orthop Relat Res. 2004; (428): 12-25.

24. Feng B, Weng X, Lin J, et al. Long term follow up of clinical outcome between patellar resurfacing and nonresurfacing in total knee arthroplasty: Chinese experience. Chin Med J (Engl). 2014; 127(22): 3845-3851.

25. Nizard RS, Biau D, Porcher R, et al. A meta-analysis of patellar replacement in total knee arthroplasty. Clinic Orth Relat Res. 2005; 432: 196-203.

26. Li S, Chen Y, Su W, Zhao J, He S, Luo X. Systematic review of patellar resurfacing in total knee arthroplasty. Int Orthop. 2011; 35(3): 305-316. doi: 10.1007/s00264-010-1109-2 


\section{APPENDIX}

Appendix I. Sample of TWAAG Questionnaire which was Sent to all Patients 12-months after their Primary TKR

$<<$ NUMBER $>>\mid<<$ TITLE $>><<$ FORENAME $>><<$ SURNAME $>>$

THESE QUESTIONS APPLY TO YOUR <<SIDE>> <<HIPKNEE>> REPLACEMENT. PLEASE CIRCLE THE ANSWER WHICH IS NEAREST TO HOWYOU FEEL

I) Are you pleased with the result? UNSURE

If you are not pleased, can you identify the reason why in the space below-

2) Do you have pain? $\quad$ BAD SOMETIMES RARELY NEVER

\begin{tabular}{lll}
\hline 3) Do you walk outside? & OFTEN SOMETIMES RARELY NEVER
\end{tabular}

4) Have you had to go to your doctor about your joint replacement? NOs

5) Are you still being seen at hospital by your surgeon? YES

6) Has there been any complication with your joint replacement? YES

If yes, please state the complication below-

7) Have you had another operation on THIS joint replacement?

If yes, please state what the operation involved below-

YES

NO

8) If you have experienced any problems with your $<<$ SIDE $>><<$ HIPKNEE $>>$ that your surgeon is unaware of, would you like us to contact them on your behalf?

9) Please feel free to comment about any aspect of your joint replacement below. 